\title{
Environmental surveillance of viruses by tangential flow filtration and metagenomic reconstruction
}

V Furtak ${ }^{1}$, M Roivainen ${ }^{2}, 0$ Mirochnichenko ${ }^{1}$, T Zagorodnyaya $^{1}$, M Laassri $^{1}$, SZ Zaidi ${ }^{3}$, L Rehman ${ }^{3}$, MM Alam $^{3}$, V Chizhikov $^{1}$ , K Chumakov ${ }^{1}$

1. Center for Biologics Evaluation and Research, US Food and Drug Administration, Silver Spring, United States

2. National Institute for Health and Welfare, Helsinki, Finland

3. WHO Regional Reference Laboratory for Polio Eradication Initiative, Department of Virology and Immunology, National Institute of Health, Islamabad, Pakistan

Correspondence: Konstantin Chumakov (konstantin.chumakov@fda.hhs.gov)

Citation style for this article:

Furtak V, Roivainen M, Mirochnichenko O, Zagorodnyaya T, Laassri M, Zaidi SZ, Rehman L, Alam MM, Chizhikov V, Chumakov K. Environmental surveillance of viruses by tangential flow filtration and metagenomic reconstruction. Euro Surveill. 2016;21(15):pii=30193. DOl: http://dx.doi.org/10.2807/1560-7917. ES.2016.21.15.30193

Article submitted on 14 July 2015 / accepted on 14 April 2016 / published on 14 April 2016

An approach is proposed for environmental surveillance of poliovirus by concentrating sewage samples with tangential flow filtration (TFF) followed by deep sequencing of viral RNA. Subsequent to testing the method with samples from Finland, samples from Pakistan, a country endemic for poliovirus, were investigated. Genomic sequencing was either performed directly, for unbiased identification of viruses regardless of their ability to grow in cell cultures, or after virus enrichment by cell culture or immunoprecipitation. Bioinformatics enabled separation and determination of individual consensus sequences. Overall, deep sequencing of the entire viral population identified polioviruses, non-polio enteroviruses, and other viruses. In Pakistani sewage samples, adenoassociated virus, unable to replicate autonomously in cell cultures, was the most abundant human virus. The presence of recombinants of wild polioviruses of serotype 1 (WPV1) was also inferred, whereby currently circulating WPV1 of south-Asian (SOAS) lineage comprised two sub-lineages depending on their non-capsid region origin. Complete genome analyses additionally identified point mutants and intertypic recombinants between attenuated Sabin strains in the Pakistani samples, and in one Finnish sample. The approach could allow rapid environmental surveillance of viruses causing human infections. It creates a permanent digital repository of the entire virome potentially useful for retrospective screening of future discovered viruses.

\section{Introduction}

Surveillance for the presence of pathogenic viruses is important for development of rational disease control strategies. It is an integral part of the worldwide campaign to stop the transmission of wild and vaccinederived polioviruses (VDPV). The campaign uses oral polio vaccine (OPV) made from attenuated strains of three serotypes of poliovirus that can mutate and become virulent VDPVs. The progress of the campaign is monitored by detecting cases of acute flaccid paralysis (AFP) followed by virological confirmation by serological methods, polymerase chain reaction (PCR) tests, and partial nucleotide (nt) sequencing [1-3]. AFP has infectious and non-infectious causes and therefore polio surveillance involves processing of a large number of samples, most of which do not contain poliovirus. An extensive laboratory network is involved in this activity, making it labour-intensive, time-consuming, and expensive.

The sensitivity of AFP surveillance is inherently limited because in a fully susceptible population only a small fraction of infections leads to AFP. In immunised communities, infection to paralysis ratio is even higher, allowing polioviruses causing AFP to transmit silently $[4,5]$. Confirmation that poliovirus circulation has stopped must be based on detection of poliovirus itself rather than its clinical manifestations. Poliovirus could be consistently isolated from the environment in regions with no recorded cases of paralytic polio $[2,4,6]$. Highly evolved VDPVs that may have been excreted by unidentified chronically infected individuals have also been found [7-9].

Current sewage concentration methods are based on two-phase separation [10-12], absorption onto membrane filters [13], and other protocols [14]. While some of these allow only a qualitative characterisation of viruses present in a sample, others, such as two-phase separation can also provide quantitative data. The performance of these methods is however affected by sample $\mathrm{pH}$ and the presence of different impurities $[15,16]$. Traditional size-selective ultrafiltration is impractical because filters are rapidly blocked by impurities. In contrast, devices in which liquid moves tangentially 


\section{FIGURE 1}

Depth of sequencing coverage and SimPlot analysis of recovered sequences generated by analysis of whole RNA libraries derived from two cell cultures, each infected with a different sewage sample collected in the Helsinki region, Finland, 2013

A.

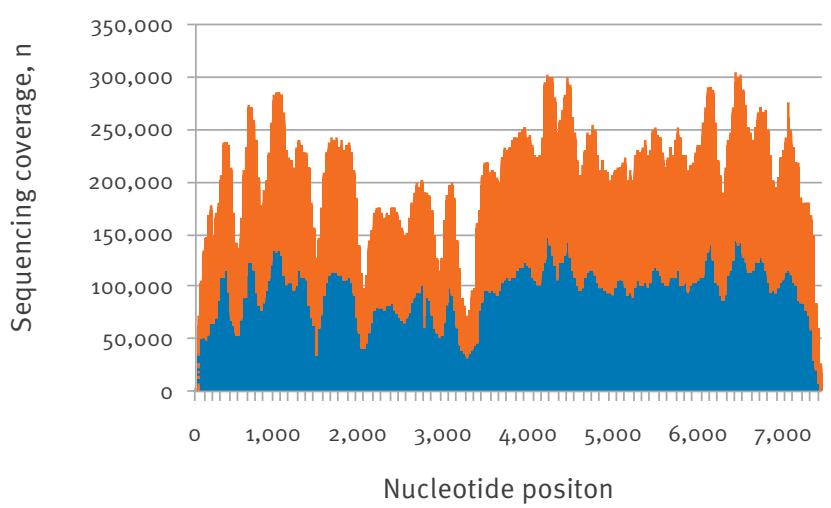

C.

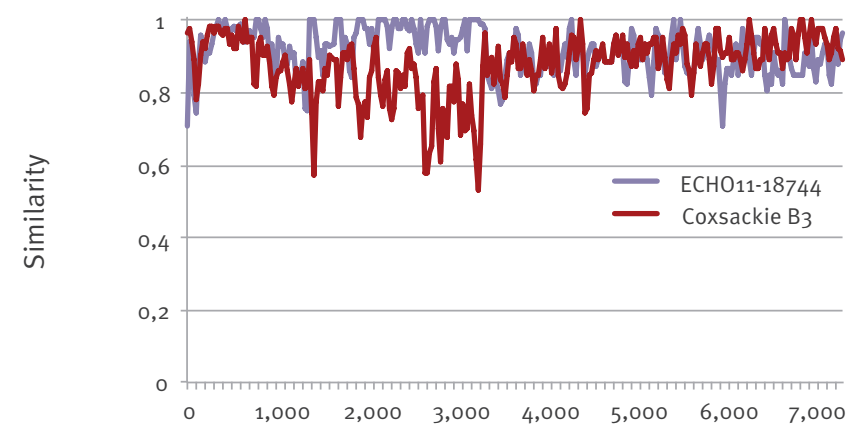

Nucleotide positon
B.

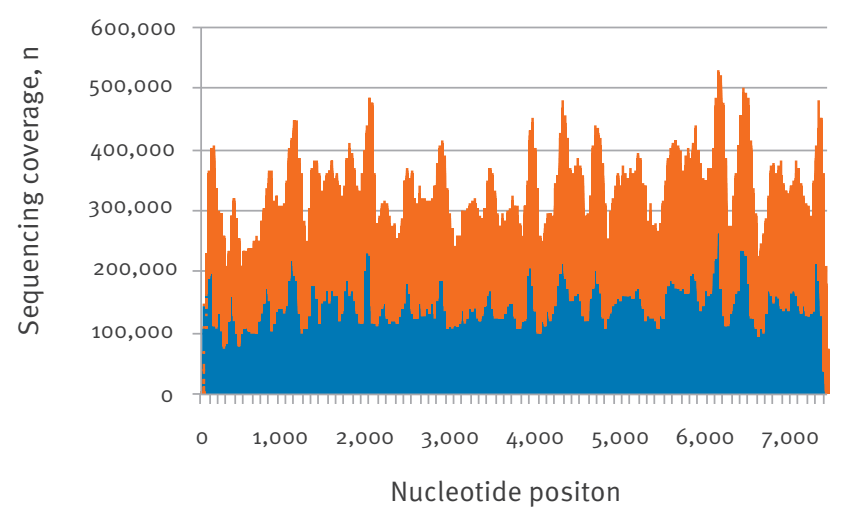

D.

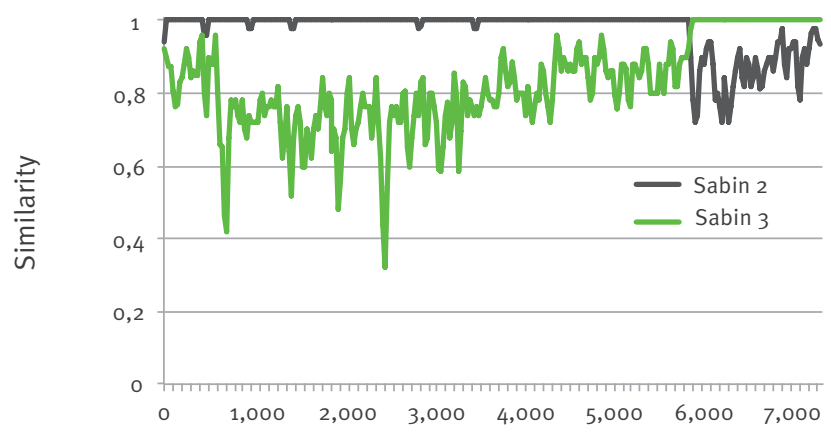

Nucleotide positon

A. Depth of sequencing coverage generated by analysis of whole RNA library derived from a RD cell culture infected with sewage sample F1. This sewage sample was a priori shown not to contain poliovirus by a standard World Health Organization procedure using strain-specific polymerase chain reaction [21]. Red and blue indicate forward and reverse sequencing reads, respectively.

B. Depth of sequencing coverage generated by analysis of whole RNA library derived from a L2oB cell culture infected with sewage sample F2. This sewage sample was a priori shown to contain poliovirus. Red and blue indicate forward and reverse sequencing reads, respectively.

C. SimPlot diagram generated using consensus sequences of the virus present in F1 sewage sample compared with coxsackievirus B3 and echovirus 11, accession numbers AY752944 and AJ276224.

D. SimPlot diagram generated using consensus sequences of the virus present in F2 sewage sample compared with Sabin 2 and Sabin 3 , accession numbers AY184220 and AY184221.

to the filter surface (tangential flow filtration, TFF) prevent the significant reduction of flow rates. TFF was successfully used for concentration of viruses, bacteria, and parasites from environmental samples [17-19].

Conventional protocols for the identification of polioviruses in sewage concentrates include cultivation in cell cultures susceptible to poliovirus $[12,20]$, followed by identification using strain-specific PCR and partial sequencing of their genomes [21]. The process is quite laborious and is often complicated by the presence of a mixture of viruses. Massively parallel or deep sequencing generates vast amounts of sequence information and is often used for the analysis of heterogeneous viral populations and metagenomic studies. Metagenomics have many applications in the environmental sciences [22-24] and were also successfully used for the identification of respiratory viruses in clinical samples [25]. Here we explore the utility deep sequencing for the analysis of TFF-concentrated environmental samples.

\section{Methods}

\section{Tangential flow ultrafiltration of sewage samples}

$0.5 \mathrm{~L}$ sewage samples were collected in 2013 in the Helsinki region of Finland (two samples) and Islamabad, Pakistan (eight samples). They were centrifuged for $10 \mathrm{~min}$ at $3,000 \mathrm{~g}$ resulting in a solid and liquid fraction. The solid (sludge) fraction was 
Comparison of sequence diversity profiles in two sewage samples with heterogeneous and homogeneous viral populations, Finland 2013

A.

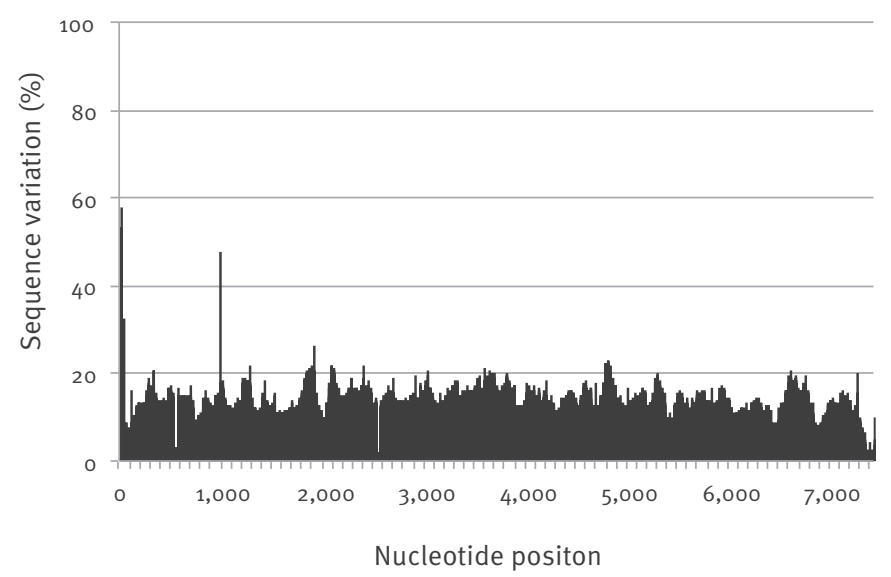

B.

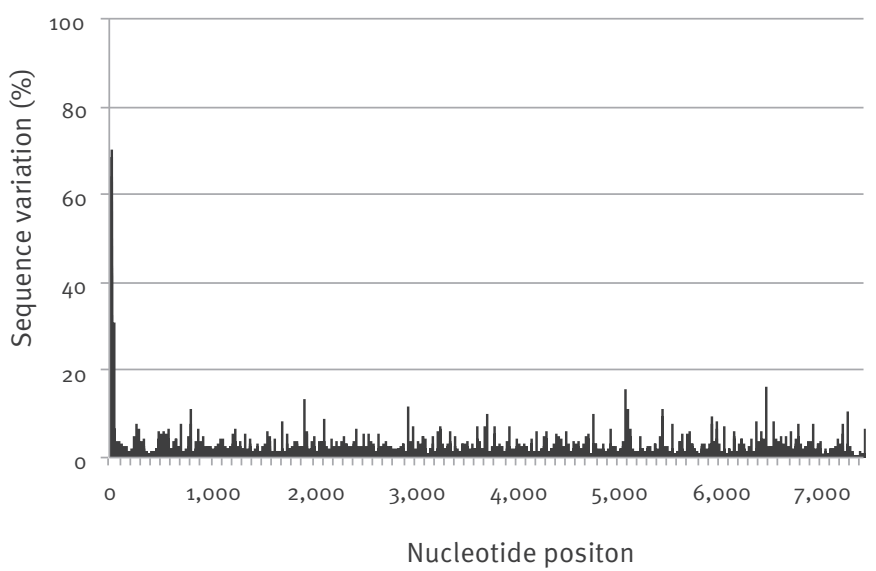

A. Sequence profiles of the F2 sewage sample containing a virus ca $16 \%$ distant from the major viral population.

B. Sequence profile of another sewage sample with a more homogenous viral population

re-suspended and homogenised by Omni homogenizer in $25 \mathrm{~mL}$ of $25 \%$ beef extract, and the resulting particulate fraction removed by centrifugation at $3,000 \mathrm{~g}$ for $10 \mathrm{~min}$. The supernatant was combined with the previously obtained liquid fraction and filtered through a $0.2 \mu \mathrm{m}$ MidiKros TFF filter (Spectrum Laboratories Inc., Rancho Dominguez, CA) followed by rinsing the filter with $10 \mathrm{~mL}$ of $25 \%$ beef extract. In some cases liquid and solid (i.e. supernatant obtained from elution with beef extract) fractions were processed separately. Next, virus concentration was performed using an automated Spectrum Laboratories KrosFlo Research Ili TFF system and $100 \mathrm{kDa}$ molecular weight cut-off MidiKros filters at 9 psi trans-membrane pressure and $60 \mathrm{~mL} / \mathrm{min}$ flow rate to the final volume of ca $5 \mathrm{~mL}$ (the void volume of the TFF system). The volume was further reduced to $0.5-0.8 \mathrm{~mL}$ by manually operating two $5-\mathrm{mL}$ syringes attached to TFF cartridge disconnected from the TFF system.

\section{Isolation of viruses in cell cultures}

Sewage concentrates were diluted in Dulbecco minimal essential medium (DMEM) to a final volume of $3 \mathrm{~mL}$ and inoculated into cultures of rhabdomyosarcoma (RD) cells and incubated in a $5 \% \mathrm{CO}_{2}$ atmosphere at $37^{\circ} \mathrm{C}$ for 1-7 days until cytopathic effect (CPE) developed. The harvest from RD cultures was inoculated into $L 20 B$ cell cultures (mouse $L$ cells expressing human poliovirus receptor $C D_{155)}$ to selectively amplify polioviruses according to the World Health Organization (WHO) protocol [13]. Culture media from CPE-positive L2OB cells and CPE-positive RD cells were used for subsequent real-time PCR analysis and/or deep sequencing.
Detection of polio and enteroviruses in sewage concentrates by real-time PCR

RNA was isolated from samples prepared by different procedures described above using NucleoSpin RNA Virus F kit (Clontech Inc., Mountain View, CA) and used for real-time PCR with strain-specific primers [25]. All $P C R$ reactions were performed in duplicate on a CFX96 Real-Time PCR system (Bio-Rad). The same RNA samples were also used for deep sequencing.

\section{Titration of Sabin 1 poliovirus in spiked sewage samples}

$0.5 \mathrm{~mL}$ of $2 \times 10^{5}$ cell culture infectious doses (CCID ${ }_{50}$ of Sabin 1 poliovirus diluted in phosphate buffered saline (PBS) was added to $0.5 \mathrm{~L}$ of poliovirus-free sewage sample and incubated for 1 hour. Identical $0.5 \mathrm{~mL}$ virus sample served as a control. Virus titres were determined in $\mathrm{Hep} 2 \mathrm{C}$ cells by terminal dilutions method according to WHO recommendations [13]. Virus recovery was evaluated as a percentage of infectious virus relative to the control unspiked sample.

Poliovirus enrichment by immunoprecipitation and sequence-independent isothermal amplification

Biotinylated rabbit polyclonal IgG against wild polioviruses of serotypes 1,2 , and 3 were used for immunoprecipitation. Five $\mu \mathrm{L}$ of stock solution containing 0.5 $\mu \mathrm{g}$ rabbit IgG was added to $0.5 \mathrm{~mL}$ of TFF-concentrated sewage and incubated for 3 hours on a rocker. Ten $\mu \mathrm{L}$ of streptavidin-coated magnetic beads (Thermo Fisher Scientific Inc., Rockford, IL) washed with PBS were added to the TFF concentrate and incubated at room temperature for 2 hours on a rocker. Magnetic beads were then washed with DMEM and PBS and 


\section{FIGURE 3}

Phylogenetic tree showing the relatedness of viral sequences identified in F1 and F2 sewage samples to reference enterovirus strain sequences, Helsinki region, Finland, 2013

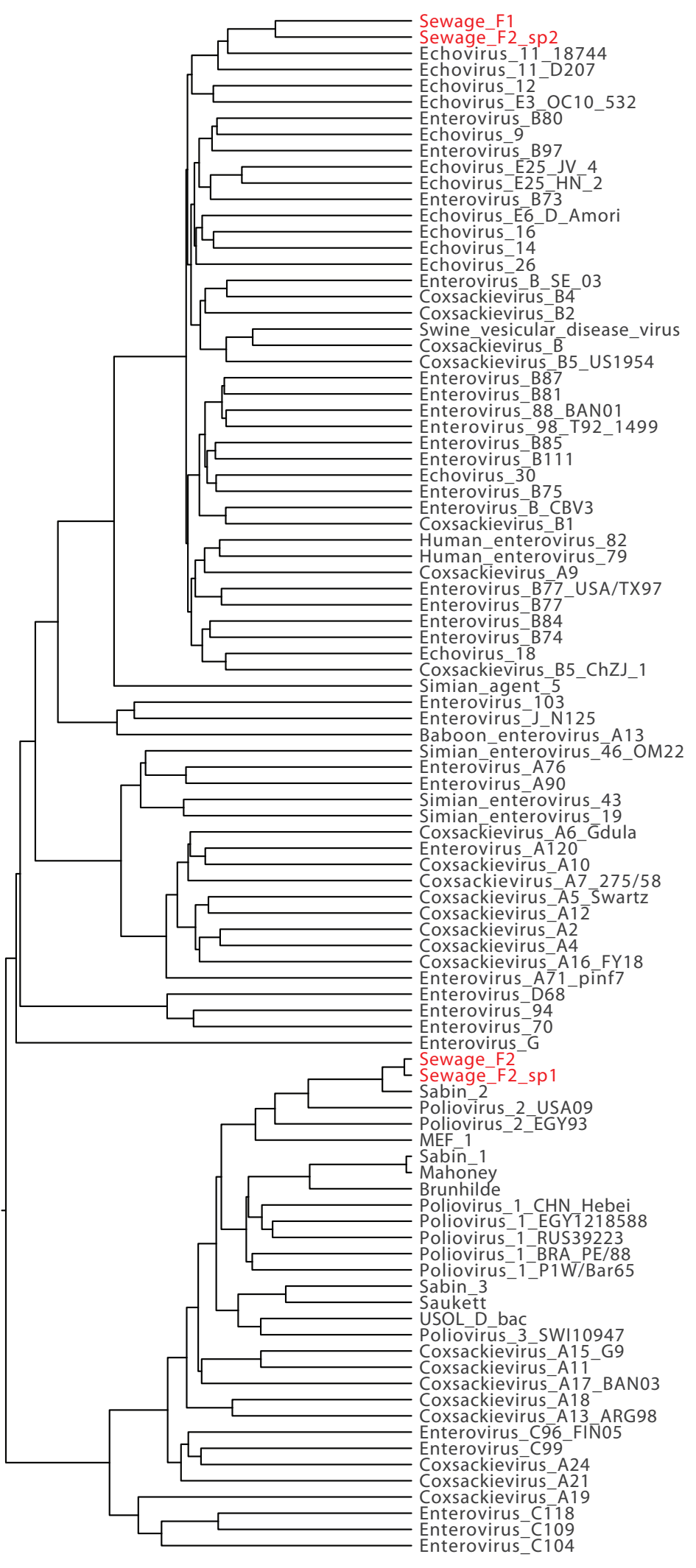

200.0

Sequences marked sp1 and sp2 were bioinformatically separated from sewage sample F2, and represent the majority and minority component, respectively. 
Simplot analyses showing recombinant structures of some polioviruses present in sewage samples collected in Islamabad, Pakistan, June-July 2013

A.

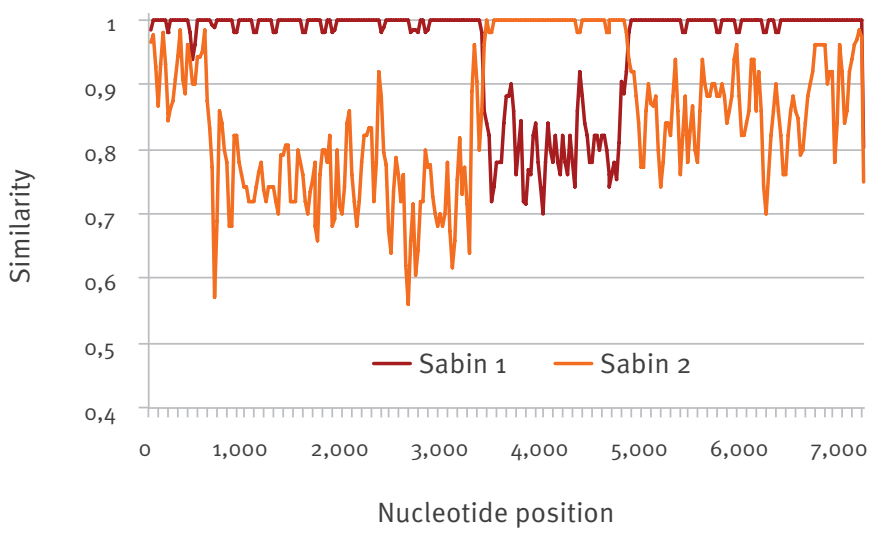

C.

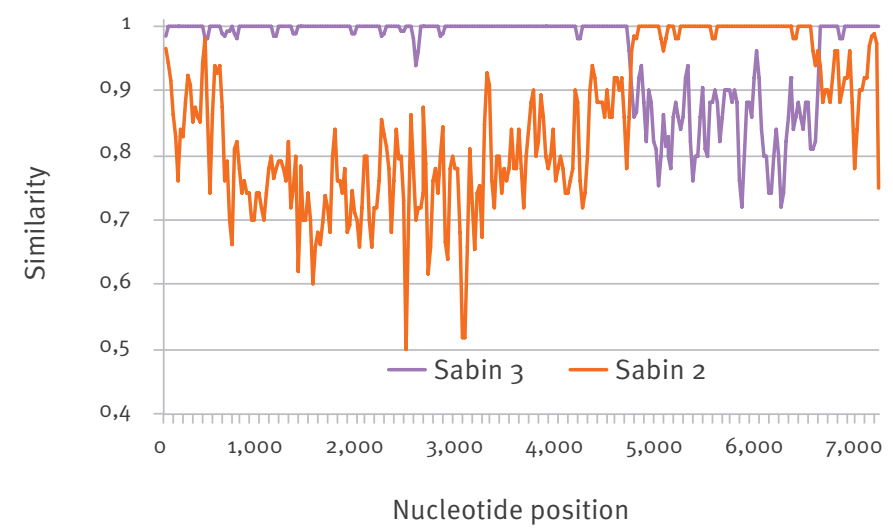

B.

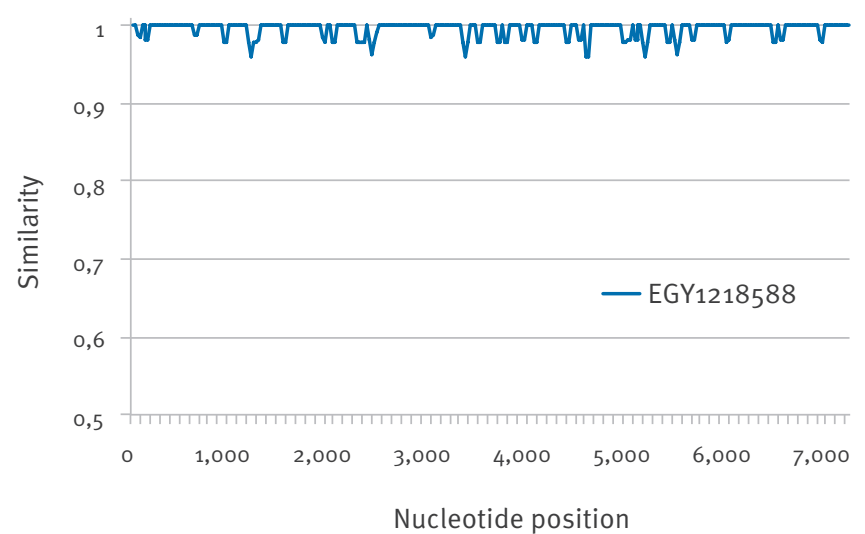

D.

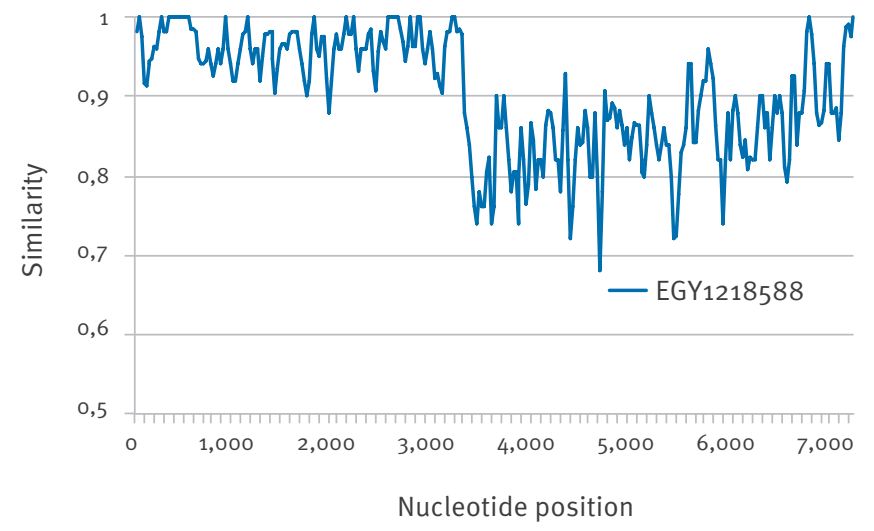

Reference sequences used for these Simplot charts were Sabin 1 (GenBank accession number: AY184219), Sabin 2 (GenBank accession number: AY184220), Sabin 3 (GenBank accession number: AY184221), and EGY1218588 (GenBank accession number: KJ155496).

A. Recombinant Sabin 1/2 virus.

B. Wild type 1 poliovirus, which, when compared to sequence entries in the entire database of published enterovirus sequences, was most similar to EGY1218588 (which belongs to the south-Asian (SOAS) lineage).

C. Recombinant Sabin 3/2 virus.

D. Wild type 1 poliovirus, which, when compared to sequence entries in the entire database of published enterovirus sequences, was most similar to EGY1218588 (which belongs to the SOAS lineage). The similarity between the virus in panel D and EGY1218588 was less than the similarity between the virus in panel B and EGY1218588. The difference between the two wild type viruses in panels B and D could be explained by a recombination event in the sequence of the virus in panel $D$ at the boundary between the $P_{1}$ and $P_{2}$ regions.

stored frozen at $-20^{\circ} \mathrm{C}$. The procedure was performed separately for each serotype of poliovirus. Isothermal amplification using REPLI-g WTA single cell kit (Qiagen, Valencia, CA) was performed according to the manufacturer's protocol.

\section{Deep sequencing}

RNA isolated from samples prepared by different procedures described above was used for total RNA Illumina library preparation using NEB NEXT Ultra RNA library kit (NEB, Ipswich, MA). The quality of libraries was assessed using the qPCR Library Quantification Kit (Kapa Biosystems, Inc., Woburn, MA) and Agilent 2100
Bioanalyzer (Agilent Technologies, Santa Clara, CA). DNA sequencing was performed on Illumina HiSeq 2000 or MiSeq to generate 100 to $300 \mathrm{nt}$ long paired-end reads. In some experiments, samples were sequenced in multiplex format (up to eight samples per sequencing lane) using unique index primers (barcodes).

\section{Bioinformatic analysis}

Bioinformatic analysis was performed using a custom 'swarm' software package developed for UNIX (Darwin) environment on MacPro (Apple Inc., Cupertino, CA) and running in parallel mode using up to 22 computation threads. Low quality sequences, adapters and index 
TABLE 1

A list of viruses identified in eight sewage samples collected in Islamabad, Pakistan, June-July 2013

\begin{tabular}{|c|c|c|c|c|c|}
\hline \multirow{2}{*}{$\begin{array}{l}\text { Sewage sample } \\
\text { name }\end{array}$} & \multirow{2}{*}{ Fraction } & \multirow{2}{*}{ Cell culture } & \multirow{2}{*}{ Majority virus } & \multicolumn{2}{|r|}{ Minority virus ${ }^{\mathrm{a}}$} \\
\hline & & & & $\%^{\mathrm{b}}$ & Description \\
\hline \multirow{6}{*}{$\mathrm{P}_{1}$} & \multirow{2}{*}{ Supernatant } & $\mathrm{RD}$ & Wt polio type 1 & 15 & Sabin 3 \\
\hline & & L2oB & Wt polio type 1 & 5 & Sabin 3 \\
\hline & \multirow{2}{*}{ Sludge } & $\mathrm{RD}$ & Coxsackievirus $\mathrm{B}_{5}$ & 50 & Sabin 1 \\
\hline & & L2oB & Wt polio type 1 & 5 & Wt Polio type 1 \\
\hline & \multirow{2}{*}{ Combined } & $\mathrm{RD}$ & Wt polio type 1 & 40 & Sabin 1, Sabin 3 \\
\hline & & L2OB & Wt polio type 1 & 2 & Sabin 1 \\
\hline \multirow{6}{*}{$\mathrm{P}_{2}$} & \multirow{2}{*}{ Supernatant } & $\mathrm{RD}$ & Wt polio type 1 & 20 & Sabin 3 \\
\hline & & L2oB & Wt polio type 1 & 15 & Sabin 3 \\
\hline & \multirow{2}{*}{ Sludge } & $\mathrm{RD}$ & Wt polio type 1 & 30 & Coxsackievirus B1 \\
\hline & & L2OB & Wt polio type 1 & 40 & Wt Polio type 1 \\
\hline & \multirow{2}{*}{ Combined } & $\mathrm{RD}$ & Wt polio type 1 & 35 & Sabin 1 \\
\hline & & L2oB & Wt polio type 1 & 15 & Sabin 3, Sabin 1 \\
\hline \multirow{2}{*}{$P_{3}$} & \multirow{2}{*}{ Combined } & $\mathrm{RD}$ & Coxsackievirus $\mathrm{B}_{5}$ & 10 & Sabin 3 , Sabin 1 \\
\hline & & L2oB & Sabin 2 & 25 & Coxsackievirus B1, B3, B5 \\
\hline \multirow{2}{*}{$\mathrm{P}_{4}$} & \multirow{2}{*}{ Combined } & $\mathrm{RD}$ & Sabin 2 & 30 & Coxsackievirus B3 \\
\hline & & L2oB & Sabin 3 & 20 & Coxsackievirus $\mathrm{B}_{5}$ \\
\hline \multirow{6}{*}{ P9 } & \multirow{2}{*}{ Supernatant } & $\mathrm{RD}$ & Sabin 3 & 15 & Coxsackievirus $\mathrm{B}_{5}$ \\
\hline & & L2oB & Sabin 3 & $--^{c}$ & $--^{c}$ \\
\hline & \multirow{2}{*}{ Sludge } & $\mathrm{RD}$ & Coxsackievirus $\mathrm{B}_{5}$ & 20 & Sabin 3 \\
\hline & & L2OB & Sabin 3 & 40 & Wt Polio type 1 \\
\hline & \multirow{2}{*}{ Combined } & RD & Coxsackievirus $\mathrm{B}_{5}$ & 50 & Sabin 3, Sabin 3/1 recombinant \\
\hline & & L2oB & Sabin 3 & 10 & Coxsackievirus B5, Sabin 3/1 recombinant \\
\hline \multirow{6}{*}{$P_{10}$} & \multirow{2}{*}{ Supernatant } & RD & Coxsackievirus $\mathrm{B}_{5}$ & 30 & Coxsackievirus $\mathrm{B}_{5}$ \\
\hline & & L2OB & Wt polio type 1 & $-^{c}$ & $-\mathrm{c}$ \\
\hline & \multirow{2}{*}{ Sludge } & $\mathrm{RD}$ & Sabin 2 & 15 & Coxsackievirus $\mathrm{B}_{3}, \mathrm{~B}_{5}$ \\
\hline & & L2OB & Sabin 2 & 5 & Sabin 1 \\
\hline & \multirow{2}{*}{ Combined } & $\mathrm{RD}$ & Sabin 2 & 50 & Coxsackievirus $\mathrm{B}_{5}$ \\
\hline & & L2OB & Sabin 2 & 35 & Coxsackievirus $\mathrm{B}_{5}$ \\
\hline & Sunornatant & $\mathrm{RD}$ & No product & $-c$ & $--^{c}$ \\
\hline & superilatalit & L2oB & Wt polio type 1 & $-^{c}$ & $-^{c}$ \\
\hline & Sludgr & $\mathrm{RD}$ & No product & $-^{c}$ & $--^{c}$ \\
\hline P11 & Sludge & L2oB & Wt polio type 1 & $-^{c}$ & $-^{c}$ \\
\hline & Combined & RD & Wt polio type 1 & $-c$ & $-^{c}$ \\
\hline & compmea & L2oB & Wt polio type 1 & 45 & Wt Polio type 1 \\
\hline & Sunernatant & $\mathrm{RD}$ & Wt polio type 1 & 50 & Sabin 2 \\
\hline & supernatant & L2oB & Sabin 2 & $-^{c}$ & $-{ }^{c}$ \\
\hline$D_{1}$ & Cludro & RD & No product & $-^{c}$ & $-^{c}$ \\
\hline$P 12$ & sluage & $\mathrm{L} 20 \mathrm{~B}$ & Sabin 1 & 20 & Sabin 3 \\
\hline & Combined & $\mathrm{RD}$ & Sabin 1 & 50 & Sabin 1 \\
\hline & & L2oB & Sabin 1 & 25 & Sabin 3 \\
\hline
\end{tabular}

Wt: wild type.

${ }^{a}$ The minority virus is inferred from the finding, next to the majority consensus sequence (of the 'majority' virus), of another consensus sequence which is reconstructed after separation of deep sequence reads using the algorithm described in the text.

${ }^{b}$ Percentage indicates the proportion of deep sequence reads that match to the alternative consensus(es).

'Only one virus (i.e. the 'majority' virus) was found in the sewage fraction considered, so there is no 'minority' virus for this fraction. 
TABLE 2

Relative abundance of the most prevalent RNA viruses present in a sewage sample collected in Pakistan, 2013

\begin{tabular}{|l|c|}
\hline Virus & $\begin{array}{c}\text { Proportions of reads } \\
\text { among all reads that } \\
\text { match the sequence of } \\
\text { a given virus } \\
(\%)\end{array}$ \\
\hline Tomato mosaic virus & 41.20 \\
\hline Cucumber green mottle mosaic virus & 26.10 \\
\hline Tobacco mild green mosaic virus & 14.20 \\
\hline Pepper mild mottle virus & 6.70 \\
\hline Tobacco mosaic virus & 6.00 \\
\hline Youcai mosaic virus & 2.00 \\
\hline Tomato mottle mosaic virus isolate $\mathrm{MX}$ 5 & 1.10 \\
\hline Adeno-associated virus - 2 & 0.50 \\
\hline Melon necrotic spot virus & 0.30 \\
\hline Poliovirus & 0.20 \\
\hline Other & 1.50 \\
\hline
\end{tabular}

sequences were removed, and the remaining reads were aligned (mapped) on curated databases of fulllength sequences of different virus groups (GenBank). The mapping procedure involved k-mer guided SmithWaterman alignment that will be described elsewhere. Profiles of sequence heterogeneity were computed, and consensus sequences were built by identifying the most frequent nts at each genomic position. In cases where significant sequence heterogeneity was detected, sequence reads were separated into discrete subpopulations using the following algorithm. Sequence reads mapped against aligned reference genomes were segregated into discrete subsets by cluster analysis performed in overlapping 'windows' of 50-100 nt covering the entire genome ('sliding window' method). The identity of each species defined in a particular window was matched with similar information obtained for the adjacent overlapping window, and propagated along the entire genome. Consensus sequences were computed for each subset of sequence reads as described above. Unique sequences of wild type polioviruses determined in this study were deposited in GenBank (accession numbers: KU161395-KU161399).

\section{Results}

Concentration of sewage samples by tangential flow filtration and recovery of viruses

The entire concentration procedure of $0.5 \mathrm{~L}$ sewage samples took ca 2 hours. Final sewage concentrates in $0.5-0.8 \mathrm{~mL}$ volume were used for RNA isolation (see above) or inoculation into cell cultures.

Analysis by the standard WHO procedure using strainspecific PCR [21] had previously shown that a sewage sample hereby named ' $\mathrm{F} 1$ ' and collected in Finland did not contain poliovirus, while another sample ' $\mathrm{F} 2$ ', from the same country, was positive for Sabin 2 poliovirus.

To determine the efficiency of the TFF protocol, the $F_{1}$ sample was spiked with $10^{5} \mathrm{CCID}_{50}$ of Sabin 1 poliovirus. The recovery of spiked poliovirus in the combined sludge/supernatant fraction was $62 \%, 84 \%$, and $93 \%$ in three independent experiments.

Sensitivity determined in spiking experiments may differ from the sensitivity of virus detection in real sewage samples. Therefore to validate the concentration method, another sewage sample F2 from Finland which was demonstrated to contain Sabin 2 poliovirus was processed by the TFF protocol. The concentrates of $F_{1}$ (poliovirus-free) and F2 were used to infect RD and then $\mathrm{L} 20 \mathrm{~B}$ cell cultures. RD cultures were virus positive for both samples, while only F2 induced CPE in L2OB cells.

Deep sequencing of cell culture-grown viruses Whole-RNA Illumina libraries prepared from supernatants of RD and $L_{2} O B$ cultures infected with $F_{1}$ and F2 concentrates were deep-sequenced using Illumina Hiseq2000. Individual sequence reads were aligned to genomic sequences of 744 representative enteroviruses. Figures $1 \mathrm{~A}$ and $1 \mathrm{~B}$ show the depth of sequencing coverage along the viral genome in forward and reverse orientations. The most prevalent nt at each genomic position was considered to represent the consensus, and all others were assumed to be single nt polymorphisms (SNP). Consensuses contained uninterrupted open reading frames coding for 2,196 and 2,208 amino acids for $F_{1}$ and $F_{2}$ samples.

Their comparison with references and SimPlot analysis revealed that the closest relative of the virus present in the $\mathrm{F}_{1}$ sample was echovirus 11 with $82 \%$ similarity in the $\mathrm{P}_{1}$ region (Figure ${ }_{1} \mathrm{C}$ ). This level of homology does not allow us to unambiguously identify the serotype of this virus.

The virus from the $\mathrm{F} 2$ sample was a recombinant of Sabin 2 and Sabin 3 viruses with the crossover at the boundary between regions coding for $3 \mathrm{C}$ protease and 3D polymerase (nt 5,959-5,981; Figure 1D). The distal part of the genome was identical to the Sabin 3 virus, while the proximal part differed from the Sabin 2 virus at six nt positions (two in 5'-untranslated region (UTR), two in viral protein $\mathrm{VP}_{2}$, one in $\mathrm{VP}_{1}$, and one in $2 \mathrm{~A}$ protein). This indicates that this was a minimally evolved vaccine poliovirus, however, it contained mutations at both sites associated with neurovirulence $\left(A_{481} \ldots . .6\right.$ in $5^{\prime}$-UTR and $\mathrm{Thr}_{143} \ldots . .$. . His in VP1).

Sequences determined by the above procedure represent consensuses of the majority component. Sequence heterogeneity profiles revealed that sewage sample F2 contained ca $16 \%$ of one or more viruses distinct from the predominant Sabin $2 / 3$ recombinant (Figure $2 \mathrm{~A}$ ). For comparison, Figure $2 \mathrm{~B}$ shows an example of the 
TABLE 3

Relative proportion of sequence reads matching the most abundant viruses detected in a sewage sample before and after enrichment by immunoprecipitation using antibodies against poliovirus

\begin{tabular}{|c|c|c|c|}
\hline Virus found before enrichment & Per cent ${ }^{\mathrm{a}}$ & Virus found after enrichment & Per cent ${ }^{\mathrm{a}}$ \\
\hline Tomato mosaic virus & 41.20 & Poliovirus & 8.90 \\
\hline Cucumber green mottle mosaic virus & 26.10 & Tobacco mild green mosaic virus & 8.30 \\
\hline Tobacco mild green mosaic virus & 14.20 & Circovirus-like genome RW-C & 6.70 \\
\hline Pepper mild mottle virus & 6.70 & Cucumber green mottle mosaic virus & 4.30 \\
\hline Tobacco mosaic virus & 6.00 & Tobacco mosaic virus & 2.70 \\
\hline Youcai mosaic virus & 2.00 & Tomato mottle mosaic virus isolate $M X_{5}$ & 2.70 \\
\hline Tomato mottle mosaic virus isolate $\mathrm{MX}_{5}$ & 1.10 & Lactococcus phage phiLC 3 & 2.00 \\
\hline Adeno-associated virus - 2 & 0.50 & Sulfolobus islandicus rod-shaped virus 1 & 2.00 \\
\hline Melon necrotic spot virus & 0.30 & Zamilon virophage & 1.90 \\
\hline Poliovirus & 0.20 & Enterococcus phage EF62phi & 1.70 \\
\hline Cosavirus A strain HCoSV-A1 & 0.10 & Cotesia congregata virus & 1.70 \\
\hline Bovine viral diarrhoea virus 1 & 0.10 & Clostridium phage phiMMPo4 & 1.50 \\
\hline Other & 0.80 & Other & 54.50 \\
\hline
\end{tabular}

a The percentages represent the proportions of reads among all reads that match the sequence of a given virus.

SNP profile of a relatively homogeneous viral sample. To separate viruses present in the mixture, individual sequence reads mapped on the aligned reference dataset were subjected to cluster analysis in a 'sliding window' format (in a series of overlapping 50-100 ntlong sections). Sequence reads separated by this procedure were assembled into full-genome consensus sequences. The majority species in F2 samples grown in $\mathrm{L} 2 \mathrm{OB}$ cells was identical to Sabin $2 / 3$ recombinant determined by building the overall consensus. The minority species in F2 sample was close to echovirus 11 virus with ca10\% differences from the virus identified in F1 sample (Figure 3).

\section{Analysis of sewage samples from polio-endemic environment}

The above results established the feasibility of using TFF concentration and deep sequencing for characterising multiple viruses present in viral populations. Next, the utility of this approach for surveillance in a country that is still endemic for poliovirus was explored. Eight sewage samples collected in Pakistan were processed as described above, concentrates were inoculated into RD and L2OB cultures, and harvested viruses were deep-sequenced. Multiple enteroviruses present in most samples were separated bioinformatically as described above. Table 1 lists discrete viruses found in these samples. We found viruses that were very close to all three Sabin vaccine strains, as well as a number of wild type 1 polioviruses. In some samples, there were also sequences related to non-polio enteroviruses, predominantly of species $B$ (coxsackievirus $B 1$, $\mathrm{B}_{3}$, and $\mathrm{B}_{5}$ ).

The approach used in this work to reconstruct genomic sequences resulted in complete or near complete genomes (in some cases missing 1-10 nt at the ends, due to low sequencing coverage of the terminal regions). It produced more phylogenetic and molecular-epidemiological information than would be available based on VP1 sequencing alone. For instance, some vaccine derivatives were found to be recombinants of two serotypes of Sabin virus, and the crossover point was easily identified by SimPlot analysis (Figure $4 \mathrm{~A}, 4 \mathrm{C}$ ). Similarly, wild type 1 of south-Asian (SOAS) lineage currently prevalent in Pakistan and Afghanistan contained two sub-lineages that could be distinguished by a recombination event at the boundary between the $\mathrm{P}_{1}$ and $\mathrm{P}_{2}$ regions (Figure $4 \mathrm{~B}, 4 \mathrm{D}$ ).

\section{Metagenomic approach}

TFF concentration followed by deep sequencing of viruses isolated in cell culture represents an improvement over the conventional protocol by providing significantly more information in a much shorter time. However, it still depends on the ability of viruses to grow in cell culture, potentially biasing the result. A totally agnostic approach based on the direct sequencing of all RNA present in sewage concentrates could produce a more complete picture. Whole-RNA Illumina libraries were prepared directly from TFF concentrates of sewage collected in Pakistan and deep sequenced. Sequence reads were aligned to reference sequences of 5,301 full length viral genomes belonging to all major groups of viruses (National Center for Biotechnology Information, Bethesda, MD). Approximately $5-8 \%$ of all sequence reads could be aligned to sequences in the viral database, and most hits belonged to plant viruses (Table 2). Separation of sequences of plant viruses into discrete subpopulations by the algorithm described above revealed the presence of full length genomes of several different viruses, including tomato mosaic 
virus, cucumber green mottle mosaic virus, tobacco mild green mosaic virus, pepper mild mottle virus, tobacco mosaic virus, Youcai mosaic virus, and tomato mottle virus (Table 2).

Surprisingly, the most represented of all animal viruses was adeno-associated virus (AAV, $0.5 \%$ of all reads) followed by poliovirus (0.2\%). Mapping of sequence reads by alignment to sequences in reference databases of individual virus families that produced a substantial number of hits during the preliminary screening, allowed the assembly of full-genome sequences of viruses present in the sample. Sequence reads aligned to sequences in the database containing 18 reference AAV sequences assembled into a full-length genome of 4,675 nt containing two open reading frames corresponding to the non-structural and the capsid proteins of the virus. Phylogenetic analysis showed that it was 97.3\% similar to AAV-2. A similar analysis performed for astroviruses revealed the presence of human astrovirus 4 , Aichi virus 1 , human parechovirus 1 , as well as several other mammalian RNA and DNA viruses (data not shown).

\section{Enrichment of tangential flow filtration-} concentrated sewage by immunoprecipitation The number of hits for most other groups of viruses was insufficient to generate good coverage allowing unambiguous assembly of complete viral genomes or reliable heterogeneity analysis. To enable a more sensitive search for specific viruses, polioviruses present in TFF concentrates were enriched by immunoprecipitation. TFF-concentrated sewage samples were incubated with biotinylated rabbit polyclonal anti-polio IgG and the virus was captured using streptavidin-coated microbeads. Complementary DNA (cDNA) from these samples was isothermally amplified using a uniform sequence-independent REPLI-g system. Table 3 shows the specificity of sequence reads from one sewage sample before and after the enrichment that resulted in poliovirus sequences becoming the predominant species. The consensus sequence assembled from these sequence reads was shown by phylogenetic analysis to be of SOAS WPV1 identical to the virus isolated from the same sewage sample in cell culture.

\section{Discussion}

This communication demonstrates that TFF can effectively concentrate viruses present in sewage by reducing the volume from ca $500 \mathrm{~mL}$ to ca $1 \mathrm{~mL}$ in approximately 2 hours. Unlike the conventional protocols $[10,12,21]$ it does not require large volumes of toxic and noxious organic solvents, removes most impurities including PCR inhibitors, and is more amenable to highthroughput implementation.

Traditionally, identification of viruses in sewage concentrates is performed by using selective cell cultures such as mouse $L 20 B$ cells that express human poliovirus receptor [20], followed by strain-specific PCR and partial nt sequencing $[10,12,21]$. The improvements proposed here include (i) the use of deep sequencing for virus identification, and (ii) direct metagenomic analysis of sewage concentrates allowing viruses to be identified without cell cultures. The main advantage of deep sequencing is that it is a universal procedure that detects multiple viruses present in mixtures, and generates complete or near-complete genome sequences that contain more molecular-epidemiological information than partial sequencing.

Thus several vaccine-related and wild type polioviruses identified in this study were found to be intertypic recombinants. Finding the recombinant Sabin $2 / 3$ poliovirus in sewage from Finland was unexpected because this country does not use oral polio vaccine (OPV). Even though this 'young' vaccine-derivative contained only six mutations compared with Sabin 2, two of them were previously linked to neurovirulent reversion. Whole genome analysis of wild polioviruses revealed that currently circulating strains in Pakistan belong to at least two sub-lineages distinguished by different origins of their $\mathrm{P}_{2}-\mathrm{P}_{3}$ region (Figure $4 \mathrm{~B}, 4 \mathrm{D}$ ).

Most samples contained more than one virus, including non-polio enteroviruses, predominantly of species $\mathrm{B}$, similar to coxsackievirus $\mathrm{B}_{1}, \mathrm{~B}_{3}, \mathrm{~B}_{5}$, and some echoviruses. However, since no sufficiently close match was found in the published database, their serotype identity could not be established unambiguously. Future expansion of the sequence database could enable more accurate identification. Nevertheless, our study demonstrates that this approach could be also used for the surveillance of all non-polio enteroviruses.

Deep-sequencing of the entire RNA content of sewage concentrates also revealed the prevalence of multiple plant viruses, consistent with previous studies of human stool samples [26]. Bioinformatic separation of deep-sequence reads belonging to different viruses allowed their assembly into several full-length genomes that were then identified by phylogenetic analysis. Surprisingly, the most prevalent animal virus in sewage from Pakistan was AAV-2. It has never been associated with any known pathology, and cannot grow in cell cultures without a helper adenovirus [27]. The epidemiology of this virus is unknown, and this observation could help to identify its niche in nature. Additional animal viruses were detected in uncultivated sewage concentrates collected in Pakistan, and their complete genomes sequenced. They included wild and attenuated polioviruses and other enteroviruses described in this paper, as well as cosaviruses, astroviruses, parechoviruses, kobuvirus (Aichi), Saffold virus, bovine viral diarrhoea virus, cricket paralysis virus, and others that were not included in this communication and will be described elsewhere.

The most intriguing aspect of this study is the possibility of a direct metagenomic approach for routine surveillance, bypassing the need for viral cell cultures. The use of this 'agnostic' metagenomic approach 
additionally raises an interesting possibility of future retrospective search for viruses unknown at the time of sample collection by aligning sequences determined in the past to reference sequences of newly discovered viruses. Therefore, the deep sequence data could serve as a digital repository of the virome present in sewage samples without the need to preserve their viability or biocontainment.

Depending on the sewage sample, a certain number of viruses were represented by a small number of sequence reads. Although these could have potentially resulted from contamination, such as carryover of a small amount of genetic material from previous sequencing runs in the laboratory, we do not believe that findings described in this report resulted from such carryover. Indeed for the viral sequences that could be reconstructed, we do not work with the corresponding viruses in our laboratory. Moreover, bleaching between sequencing runs, which helps to eliminate this problem, was regularly performed.

Low number of reads of certain viruses, however make the depth of the sequencing coverage insufficient for reliable assembly of their complete genomes. Enrichment of polioviruses from sewage concentrates by immunoprecipitation resulted in poliovirus-specific sequence reads becoming predominant in uncultivated sewage concentrates, preserving the remaining material for further screening for other viruses. As a result, the complete genome of wild type 1 poliovirus was assembled and was found to match the sequence of the virus of the SOAS lineage that was identified in this sample by the cell culture method.

In conclusion, the approach described in this paper can provide an effective alternative to current protocols used for environmental surveillance for wild polioviruses and VDPV, other non-polio enteroviruses, as well as viruses of other families. Most countries in Europe have switched to the exclusive use of Inactivated Polio Vaccines (IPV). Good protection from paralysis that it induces combined with inadequate intestinal immunity [28] allows viruses to spread silently, which makes the traditional AFP surveillance less effective. Therefore environmental surveillance using metagenomic approach in combination with TFF or other improved sewage concentration methods could be particularly useful in Europe and other countries that have switched to the use of IPV. Rapidly declining cost of deep sequencing makes this approach cost-effective compared with the conventional sequencing methods. It could significantly shorten the time needed for the identification of pathogenic viruses in the environment, allowing for a much faster deployment of countermeasures.

\section{Erratum}

The name of the author Sohail Z. Zaidi had been misspelled. This was corrected on 12 May 2016.
Acknowledgements

Authors thank Dr. Humayun Asghar of the World Health Organization for suggestions. This work was funded by the intramural research program of the US Food and Drug Administration and a grant to M.R. from the World Health Organization.

\section{Conflict of interest}

None declared.

\section{Authors' contributions}

Konstantin Chumakov and Merja Roivainen designed the study. Merja Roivainen, Sohail Z. Zaidi, Lubna Rehman, and Muhammad M. Alam collected sewage samples, Vyacheslav Furtak, Merja Roivainen, and Vladimir Chizhikov performed TFF concentration, Olga Mirochnichenko performed virus isolation, Tatiana Zagorodnyaya, Majid Laassri, and Vyacheslav Furtak performed deep sequencing. Konstantin Chumakov drafted the manuscript.

\section{References}

1. Centers for Disease Control and Prevention (CDC),. Evaluating surveillance indicators supporting the Global Polio Eradication Initiative, 2011-2012.MMWR Morb Mortal Wkly Rep. 2013;62(14):270-4.PMID: 23575241

2. Hovi T, Shulman LM, van der Avoort H, Deshpande J, Roivainen $M, D E$ Gourville EM. Role of environmental poliovirus surveillance in global polio eradication and beyond.Epidemiol Infect. 2012;140(1):1-13. DOI: 10.1017/S095026881000316X PMID: 21849095

3. Asghar H, Diop OM, Weldegebriel G, Malik F, Shetty S, E Bassioni L, et al. Environmental surveillance for polioviruses in the Global Polio Eradication Initiative. J Infect Dis. 2014;210(Suppl 1):S294-303. DOI: 10.1093/infdis/jiu384 PMID: 25316848

4. Manor Y, Handsher R, Halmut T, Neuman M, Bobrov A, Rudich $H$, et al. Detection of poliovirus circulation by environmental surveillance in the absence of clinical cases in Israel and the Palestinian authority. J Clin Microbiol. 1999;37(6):1670-5.PMID: 10325305

5. Shulman LM, Gavrilin E, Jorba J, Martin J, Burns CC, Manor $Y$, et al. Molecular epidemiology of silent introduction and sustained transmission of wild poliovirus type 1, Israel, 2013. Euro Surveill. 2014;19(7):20709. DOI: 10.2807/1560-7917. ES2014.19.7.20709 PMID: 24576471

6. El Bassioni L, Barakat I, Nasr E, de Gourville EM, Hovi T, Blomqvist $\mathrm{S}$, et al. Prolonged detection of indigenous wild polioviruses in sewage from communities in Egypt. Am J Epidemiol. 2003;158(8):807-15. DOI: $10.1093 /$ aje/kwg202 PMID: 14561671

7. Shulman LM, Manor Y, Sofer D, Handsher R, Swartz T, Delpeyroux F, et al. Neurovirulent vaccine-derived polioviruses in sewage from highly immune populations. PLoS One. 2006;1(1):e69. DOI: 10.1371/journal.pone.0000069 PMID: 17183700

8. Al-Hello H, Jorba J, Blomqvist S, Raud R, Kew O, Roivainen $M$. Highly divergent type 2 and 3 vaccine-derived polioviruses isolated from sewage in Tallinn, Estonia.J Virol. 2013;87(23):13076-80. DOI: 10.1128/JVI.01174-13 PMID: 24049178

9. Hovi T, Paananen A, Blomqvist S, Savolainen-Kopra C, AlHello H, Smura T, et al. Characteristics of an environmentally monitored prolonged type 2 vaccine derived poliovirus shedding episode that stopped without intervention. PLoS One. 2013;8(7):e66849. DOI: 10.1371/journal.pone.0066849 PMID: 23935826

10. Albertson P. Two-phase separation of viruses. In Maramorosch K, Koprowski H, eds. Methods of virology. 1967:303-21.

11. Más Lago P, Gary HE, Pérez LS, Cáceres V, Olivera JB, Puentes $\mathrm{RP}$, et al. Poliovirus detection in wastewater and stools following an immunization campaign in Havana, Cuba. Int J Epidemiol. 2003;32(5):772-7. DOI: 10.1093/ije/dyg185 PMID: 14559748 
12. World Health Organization (WHO). Guidelines for environmental surveillance of poliovirus circulation. Geneva, Switzerland: WHO; 2003.

13. Tambini G, Andrus JK, Marques E, Boshell J, Pallansch M, de Quadros CA, et al. Direct detection of wild poliovirus circulation by stool surveys of healthy children and analysis of community wastewater. J Infect Dis. 1993;168(6):1510-4. DOI: 10.1093/infdis/168.6.1510 PMID: 8245537

14. Lewis GD, Metcalf TG. Polyethylene glycol precipitation for recovery of pathogenic viruses, including hepatitis $A$ virus and human rotavirus, from oyster, water, and sediment samples. Appl Environ Microbiol. 1988;54(8):1983-8.PMID: 2845860

15. Shields PA, Farrah SR. Concentration of viruses in beef extract by flocculation with ammonium sulfate.Appl Environ Microbiol. 1986;51(1):211-3.PMID: 3006587

16. Guttman-Bass N, Catalano-Sherman J. Humic acid interference with virus recovery by electropositive microporous filters.Appl Environ Microbiol. 1986;52(3):556-61.PMID: 3021058

17. Liu P, Hill VR, Hahn D, Johnson TB, Pan Y, Jothikumar N, et al. Hollow-fiber ultrafiltration for simultaneous recovery of viruses, bacteria and parasites from reclaimed water. J Microbiol Methods. 2012;88(1):155-61. DOI: 10.1016/j. mimet.2011.11.007 PMID: 22108496

18. Smith CM, Hill VR. Dead-end hollow-fiber ultrafiltration for recovery of diverse microbes from water.Appl Environ Microbiol. 2009;75(16):5284-9. DOI: 10.1128/AEM.00456-09 PMID: 19561183

19. Thurber RV, Haynes M, Breitbart M, Wegley L, Rohwer F. Laboratory procedures to generate viral metagenomes. Nat Protoc. 2009;4(4):470-83. DOI: $10.1038 /$ nprot.2009.10 PMID: 19300441

20. Pipkin PA, Wood DJ, Racaniello VR, Minor PD. Characterisation of $L$ cells expressing the human poliovirus receptor for the specific detection of polioviruses in vitro.J Virol Methods. 1993;41(3):333-40. DOI: 10.1016/0166-0934(93)90022-J PMID: 8386181

21. Kilpatrick DR, Yang CF, Ching K, Vincent A, Iber J, Campagnoli $R$, et al. Rapid group-, serotype-, and vaccine strainspecific identification of poliovirus isolates by real-time reverse transcription-PCR using degenerate primers and probes containing deoxyinosine residues. J Clin Microbiol. 2009;47(6):1939-41. DOI: 10.1128/JCM.00702-09 PMID: 19386844

22. Dinsdale EA, Edwards RA, Hall D, Angly F, Breitbart M, Brulc $\mathrm{JM}$, et al. Functional metagenomic profiling of nine biomes. Nature. 2008;452(7187):629-32. DOI: 10.1038/nature06810 PMID: 18337718

23. Cantalupo PG, Calgua B, Zhao G, Hundesa A, Wier AD, Katz JP, et al. Raw sewage harbors diverse viral populations. MBio. 2011;2(5):e00180-11. DOI: 10.1128/mBio.00180-11 PMID: 21972239

24. Ng TF, Marine R, Wang C, Simmonds P, Kapusinszky B Bodhidatta $L$, et al. High variety of known and new RNA and DNA viruses of diverse origins in untreated sewage. J Virol. 2012;86(22):12161-75. DOI: 10.1128/JVI.00869-12 PMID: 22933275

25. Prachayangprecha S, Schapendonk CM, Koopmans MP, Osterhaus AD, Schürch AC, Pas SD, et al. Exploring the potential of next-generation sequencing in detection of respiratory viruses. J Clin Microbiol. 2014;52(10):3722-30. DOI: 10.1128/JCM.01641-14 PMID: 25100822

26. Zhang T, Breitbart M, Lee WH, Run JQ, Wei CL, Soh SW, et al. RNA viral community in human feces: prevalence of plant pathogenic viruses. PLoS Biol. 2006;4(1):e3. DOI: 10.1371/ journal.pbio.0040003 PMID: 16336043

27. Mueller C, Flotte TR. Clinical gene therapy using recombinant adeno-associated virus vectors.Gene Ther. $2008 ; 15(11): 858-63$. DOI: $10.1038 /$ gt.2008.68 PMID: 18418415

28. Plotkin SA, Vidor E. Poliovirus vaccine -- inactivated. In: Plotkin SA, Orenstein WA, Offit PA, editors. Vaccines. 5 ed. Philadelphia: W.B. Saunders; 2008. p. 605-29.

\section{License and copyright}

This is an open-access article distributed under the terms of the Creative Commons Attribution (CC BY 4.0) Licence. You may share and adapt the material, but must give appropriate credit to the source, provide a link to the licence, and indicate if changes were made.

This article is copyright of the authors, 2016. 